\title{
Meckel-Gruber syndrome: a rare and lethal foetal anomaly
}

\author{
Parikshit Jondhale, Mohit Marda, Vidyadhar B. Bangal*, Nikita Bagdi
}

Department of Obstetrics and Gynecology, Rural Medical College, Pravara Institute of Medical Sciences, Loni, Ahmednagar, Maharashtra, India

Received: 27 April 2020

Accepted: 30 May 2020

\section{*Correspondence:}

Dr. Vidyadhar B. Bangal,

E-mail: vbb217@rediffmail.com

Copyright: (c) the author(s), publisher and licensee Medip Academy. This is an open-access article distributed under the terms of the Creative Commons Attribution Non-Commercial License, which permits unrestricted non-commercial use, distribution, and reproduction in any medium, provided the original work is properly cited.

\begin{abstract}
Meckel-Gruber syndrome (MGS) is a rare and lethal autosomal recessive disorder characterized by occipital encephalocele, postaxial polydactyly and bilateral dysplastic cystic kidneys. It can be associated with many other congenital malformations. The incidence of Meckel-Gruber syndrome ranges between 1 in 13,000 to 4,00,000 live births. Antenatal ultrasound examination establishes the diagnosis by identifying at least two of the major features. A case is presented that describes a baby with ambiguous genitalia, who presented with the triad of Meckel-Gruber syndrome. The baby died shortly after birth.
\end{abstract}

Keywords: Autosomal recessive disorder, Encephalocele, Meckel-Gruber syndrome, Polydactyly, Renal cystic dysplasia

\section{INTRODUCTION}

Meckel-Gruber syndrome (MGS) was first described by Meckel JR in 1822. It is an autosomal recessive disorder, and is caused by the failure of mesodermal induction. ${ }^{1}$ Meckel-Gruber syndrome (MGS) is rare and lethal disorder, with the incidence ranging between 1 in 13,000 to $4,00,000$ live births. MGS is characterized by multisystem developmental malformations with classical features of renal cystic dysplasia, occipital encephalocele and post-axial polydactyly. ${ }^{2}$

\section{CASE REPORT}

A 20-year-old, unbooked primigravida with 39 weeks of gestation was admitted in active labour. She did not have any antenatal visits and had not undergone obstetric sonography throughout the pregnancy. On general examination, her vital parameters were stable. On per abdominal examination, uterus was full term, 3 contractions per 10 minutes present, fetus was in longitudinal lie in breech presentation with fetal heart rate of 120 beats per minute. On per vaginal examination, cervix was $4-5 \mathrm{~cm}$ dilated, $50 \%$ effacement, membrane present. Pelvis was adequate for the baby.

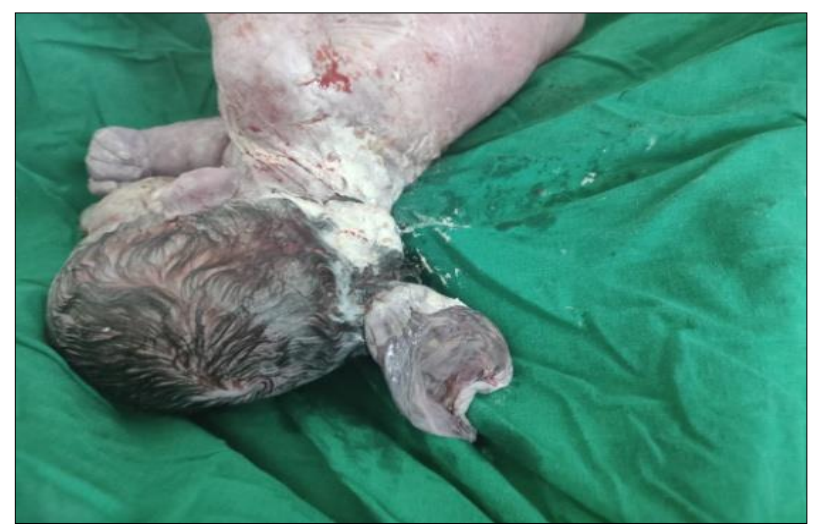

Figure 1: Occipital encephalocele.

Clinical diagnosis of primi with full term pregnancy with Breech presentation with fetal distress in active labour was made. She was immediately shifted to OT for emergency LSCS under spinal anesthesia. A grossly 
anomalous live male baby with severe birth asphyxia was delivered. Baby was resuscitated by pediatrician. Baby Apgar score was 1 at 1 minute and 0 at 5 minutes. On detailed examination of the baby, it was observed that there were multisystem developmental malformations like, occipital encephalocele (Figure 1), polydactyly of fingers and toes (Figure 2 and Figure 3) fetal ascites and ambiguous genitalia (Figure 4) and cleft palate. On post mortem ultra-sonography and CT scan of the baby showed hugely distended urinary bladder, pericardial effusion, choroid plexus cysts on right side, bilateral multiple dysplastic kidneys, gall bladder sludge, multiple cysts in liver and ventriculomegaly. Clinical post-mortem of the baby was done to confirm the imaging findings.

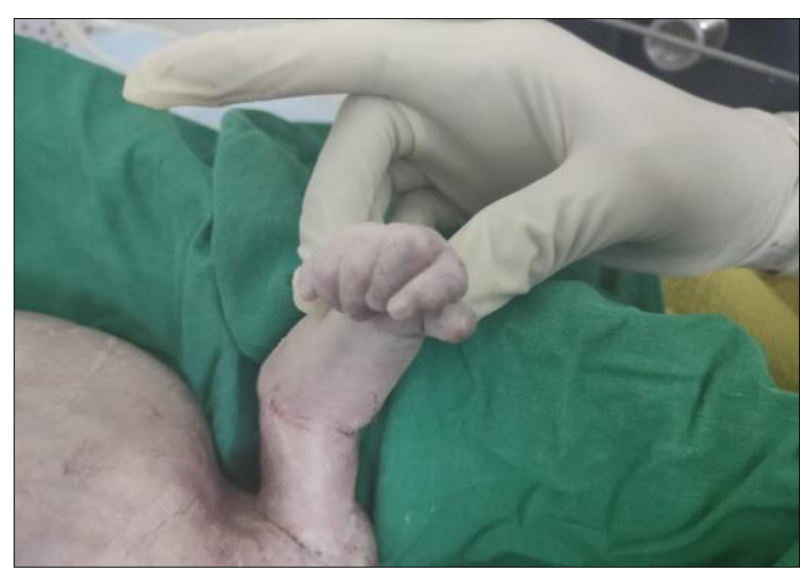

Figure 2: Polydactyly of hand.

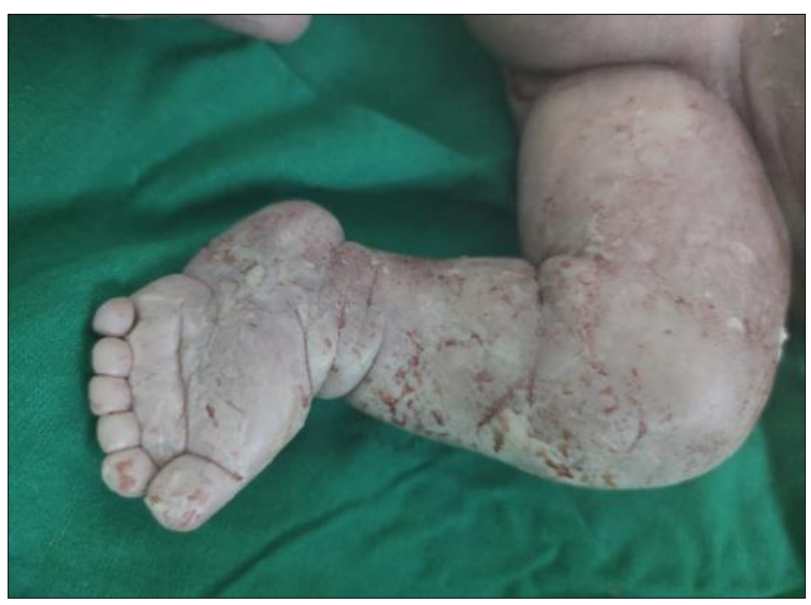

Figure 3: Polydactyly of toes.

\section{DISCUSSION}

Worldwide, the incidence of Meckel-Gruber syndrome is 1 per 13,250-140,000 live births. Individuals of finish origin have a higher incidence (1 per 9000 live births, one person in 50 is a carrier). The incidence is also higher among Belgians in Kuwait, with 1 affected birth in 3,500 (carrier rate 1 in 30). The highest incidence is reported in the Indians, with 1 affected birth per 1,300 (carrier rate, 1 in 18$)^{3}$

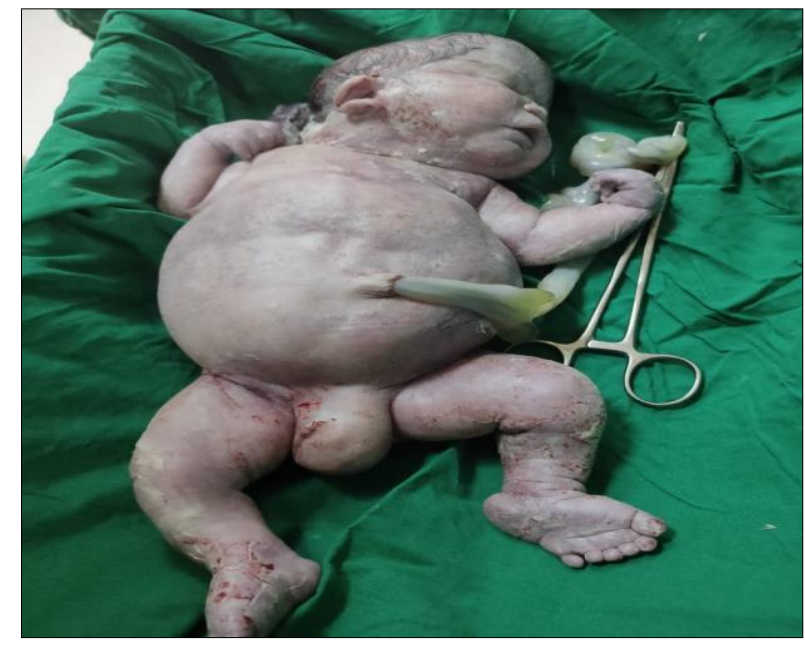

Figure 4: Ambiguous genitalia.

MGS is a lethal syndrome, causing anomalies of the central nervous system (CNS), cystic dysplasia of the kidneys, and malformations of the extremities. Other anomalies associated with MGS are intrauterine growth retardation (IUGR), single umbilical artery, cardiovascular defects, cleft palate, several genital abnormalities, and oligohydramnios and hepatic periportal fibrosis. ${ }^{4}$ Previous studies state that $57 \%$ of MGS cases had the three cardinal features, $16 \%$ had only polycystic kidney and polydactyly, and the rest exhibited other variations. ${ }^{5}$ The phenotypic variability of MGS might be due to several gene mutations. Genetic mapping of the syndrome is still incomplete, and the most frequently responsible genes are MKS1 on chromosome 17, MKS2 on chromosome 11 and MKS3 on chromosome. ${ }^{4,6,7,8}$ Chromosome analysis is essential to exclude trisomy 13, which mimics Meckel-Gruber syndrome. Trisomy 13 carries a $1 \%$ recurrence risk, as opposed to the $25 \%$ recurrence rate for Meckel-Gruber syndrome. Linkage or mutation analysis is not yet available. $^{3}$

Commonly encountered CNS abnormalities associated with MGS previously reported in the literature include occipital encephalocele, microcephaly, Dandy-Walker malformation and holoprosencephaly. ${ }^{4}$ The less frequently reported CNS anomalies of MGS include anencephaly and hydrocephaly. ${ }^{3}$ The differential diagnosis of MGS includes trisomy 13, trisomy 18 , Joubert syndrome, Bardet-Biedl syndrome and SmithLemli-Opitz syndrome. ${ }^{8}$ Trisomy 13 is the most likely syndrome to be confused with MGS. Enlarged kidneys, severe oligohydramnios and the presence of an occipital cephalocoele favors the diagnosis of MGS, whereas holoprosencephaly or other midline CNS anomalies favors trisomy. ${ }^{10}$

MGS is best diagnosed prenatally by ultrasonography early in the second trimester. Prenatal ultrasound is currently the best method available to diagnose MeckelGruber syndrome and is available in 2-dimensional (2D), 
3-dimensional (3D), and 4-dimensional (4D) modalities. The latter is particularly useful in assessing facial features and deformities, musculoskeletal malformations, and limitation of movement. MRI is a valuable complement to ultrasonography in assessing fetal anomalies in the presence of severe oligohydramnios. It is mainly used when ultrasonography findings are inconclusive or are insufficient to guide treatment choices. ${ }^{10}$

No specific biochemical and chromosomal studies indicate the presence of the MGS. Therefore, the prenatal ultrasonography detection of MGS is important for the diagnosis, which can be confirmed later by genetic analysis and careful post-mortem examination to establish the diagnosis. Clinical diagnosis is suggested on the basis of the presence of classical clinical features and when the syndrome recurs in subsequent pregnancies. ${ }^{9,11}$ Due to financial constraints, chromosomal study was not performed. Postnatal USG, computerized tomography and post mortem findings were useful in coming to the diagnosis OGF Meckel's syndrome. The chance of giving birth to another child with MGS is 1 in 4 (25\%) for each pregnancy. ${ }^{6,9}$ MGS is a fatal disorder resulting in intrauterine or early neonatal death, thus prenatal genetic counselling and prenatal diagnosis is important to explain the chances of recurrence in subsequent pregnancies. $^{11}$

The mortality is $100 \%$ and most babies die in utero or shortly after birth. Pulmonary hypoplasia is the leading cause of death. Other causes include liver and renal failure. ${ }^{12}$ Most infants are stillborn or die in hours or days after birth. A few patients sometimes survive a few months with poor quality of life. According to Ramadani, there is one report of a long survivor who died at the age of 28 months. ${ }^{13}$ In 1995, Paavola reported another atypical case of a long survivor who died at 18 months of life. $^{14}$

\section{CONCLUSION}

The Meckel-Gruber syndrome is a rare anomaly with very high for recurrence. Health care providers should use a systematic approach for birth defects, to allow accurate diagnostic and recurrence risk counselling, informed management decisions. Although improved prenatal testing has increased the detection of fetal abnormalities, an autopsy remains valuable, as it provides morphological confirmation.

Funding: No funding sources Conflict of interest: None declared Ethical approval: Not required

\section{REFERENCES}

1. Myageri A, Grampurohit V, Rao R. Meckel gruber syndrome: report of two cases with review of literature. J Fam Med Primary Care. 2013;2:106-8.

2. Abdelmoneim EM. Kheir Meckel-Gruber syndrome: a rare and lethal anomaly. Sudan $\mathbf{J}$ Paediatr. 2012;12(1):93-6.

3. Salonen R, Norio R, Reynolds James F. The Meckel syndrome: clinico-pathological findings in 67 patients. Am J Med Genet. 1984;4:671-89.

4. Nergiz S, Sezer SD, Altınkaya SÖ, Küçük M, Yüksel H. Meckel Gruber syndrome-a case report and review of literature. Gynecol Obstet Reprod Med. 2016;20.

5. Gupta M, Mehta A, Gupta R, Gupta R, Singh S. Prenatal diagnosis of Meckel-Gruber syndrome with Dandy Walker malformation. JK Sci J Med Educ Res. 2005;7:164-6.

6. Yuksel MA, Mammadov Z, Sofiyeva N, AliciDavutoglu E, Temel Yuksel I, Madazli R. An unusual case of Meckel-Gruber syndrome (MKS) associated with viscera-atrial heterotaxy and facial anomalies. J Obstet Gynaecol. 2016;36:524-5.

7. Itchimouh $\mathrm{S}$, Khabtou $\mathrm{K}$, Mahdaoui $\mathrm{S}$, Boufettal $\mathrm{H}$, Samouh N. Syndrome de Meckel Gruber: à propos d'un cas rare. Pan Afr Med J. 2016;25:43.

8. Jeevika M, Reddy TA, Kumar KA, Konareddy R. Meckel Gruber syndrome-a case report. IOSR J Dent Med SciVer III. 2016;15:2279-861.

9. Nyberg DA, Hallesy D, Mahony BS, Hirsch JH, Luthy DA, Hickok D. Meckel-Gruber syndrome. Importance of prenatal diagnosis. J Ultrasound Med. 1990;9:691-6.

10. Behairy NH, Talaat S, Saleem SN, El-Raouf MA. Magnetic resonance imaging in fetal anomalies: What does it add to 3D and 4D US?. Eur J Radiol. 2009;74(1):250-5.

11. Vernekar JA, Mishra G, Pinto R, Bhandari M, Mishra M. Antenatal ultrasonic diagnosis of Meckel Gruber syndrome (a case report with review of literature). Australas Radiol. 1991;35:186-8.

12. Chen CP. Meckel syndrome: genetics, perinatal findings, and differential diagnosis, Taiw. J Obs Gyne. 2007;46(1):9-14.

13. Ramadani HM, Nasrat HA. Prenatal diagnosis of recurrent Meckel syndrome. Int J Gynecol Obstet. 1992;39:327-32.

14. Paavola P, Salonen R, Weissenbach J. The locus for Meckel syndrome with multiple congenital anomalies maps to chromosome 17q21-q24. Nat Genet. 1995;11(2):213-5.

Cite this article as: Jondhale $\mathrm{P}$, Marda $\mathrm{M}$, Bangal

VB, Bagdi N. Meckel-Gruber syndrome: a rare and lethal foetal anomaly. Int J Reprod Contracept Obstet Gynecol 2020;9:3063-5. 